\title{
The Induction of Metabolic Alkalosis by Correction of Potassium Deficiency*
}

\author{
Howard L. Bleich, $\nmid$ Richard L. Tannen, $\dagger$ and William B. Schwartz $\ddagger$ \\ (From the Department of Medicine, Tufts University School of Medicine and the Renal \\ Laboratory, New England Medical Center Hospitals, Boston, Mass.)
}

Recent studies in both dog and man have challenged the widely held concept that repair of potassium deficiency is a prerequisite to the correction of metabolic alkalosis; ready and sustained correction of alkalosis has been shown to follow the administration of chloride, as either sodium chloride or hydrochloric acid, even when the diet is free of potassium (1-4). Furthermore, it has been shown that correction of an alkalosis by hydrochloric acid is sometimes retarded by the simultaneous repair of potassium and sodium deficiency (3). In view of these observations an attempt has been made to explore further the relationship between the retention of potassium and the renal regulation of acid-base equilibrium. For this purpose potassium-depleted animals with normal plasma bicarbonate concentrations were maintained on an electrolyte-free intake and then fed potassium with a poorly reabsorbable anion, either sulfate or phosphate. The data demonstrate that this experimental procedure induced a striking retention of potassium, a virtually equivalent increase in the renal excretion of acid, and a sustained metabolic alkalosis.

\section{Methods}

Balance studies were carried out on six female mongrel dogs weighing between 18.3 and $26.3 \mathrm{~kg}$. The dogs had been prepared according to the following protocol, which is described in greater detail in the previous paper (3) : Animals were placed on an electrolyte-free diet supplemented daily with $40 \mathrm{mEq}$ of sodium and $40 \mathrm{mEq}$ of potassium as the neutral phosphate. Metabolic alkalosis, hypokalemia, and potassium deficiency were then in-

* Submitted for publication August 24, 1965 ; accepted December 16, 1965.

Supported in part by grants H-759 and HE 5309 from the National Heart Institute.

$\dagger$ Work done during tenure of a postdoctoral research fellowship of the U. S. Public Health Service.

¥Address requests for reprints to Dr. William B. Schwartz, New England Center Hospital, 171 Harrison Ave., Boston, Mass. 02111. duced by gastric drainage of hydrochloric acid. After drainage had been completed and a steady state of alkalosis achieved, the electrolyte supplement was withdrawn from the diet, and hydrochloric acid was administered until plasma bicarbonate and $\mathrm{pH}$ returned to control values. During the next 5 to 7 days, despite the presence of severe potassium depletion, a new steady state was reached in which the acid-base composition of extracellular fluid was normal and net acid excretion was virtually constant (3).

The present study was initiated with the last 4 to 5 days of the steady state of the period after acid ingestion as the control period. Eighty $\mathrm{mEq}$ of potassium, as either sulfate (three dogs) or neutral phosphate (three dogs), was then added to the daily diet and potassium administration continued until a new steady state had clearly been achieved ( 7 to 10 days). At this time, in order to evaluate further the possible effects of sulfate as compared with phosphate, we substituted phosphate for sulfate in two dogs and continued balance observations for 5 days. Potassium phosphate was then withdrawn from the diet of these two dogs as well as from the diet of one dog that had received phosphate initially. Balance studies were terminated 7 to 8 days later.

The experimental procedures, analytical methods, and balance data calculations were identical to those described in the preceding paper ( 3 ).

\section{Results}

\section{Status of dogs before potassium administration}

Before administration of potassium mean plasma $\mathrm{pH}$ was 7.43 , and mean plasma electrolyte concentrations were bicarbonate, 22.1; sodium, 146; potassium, 2.4; and chloride, $106 \mathrm{mEq}$ per $\mathrm{L}$. Cumulative balance data for all dogs before the administration of potassium are presented in $\mathrm{Ta}$ ble I. Cumulative balances averaged chloride, -36 ; sodium, +1 ; and potassium, $-179 \mathrm{mEq}$ [ $\mathrm{Kn}(\mathrm{K}$ corrected for $\mathrm{N}),-202 \mathrm{mEq}$ ].

\section{Potassium administration}

The changes in plasma composition, potassium balance, and urinary net acid excretion for one dog given potassium sulfate and another given potas- 
TABLE I

Cumulative electrolyte balance before administration of potassium

\begin{tabular}{lcccccc}
\hline \hline \multicolumn{1}{c}{ Dog } & Days* & $\mathrm{Na}$ & $\mathrm{K}$ & $\mathrm{Kn} \dagger$ & $\mathrm{Cl}$ & $\mathrm{N}$ \\
\hline & & & \multicolumn{3}{c}{$m E q$} \\
947 & 24 & -51 & -114 & -153 & -28 & +14.1 \\
$958 \ddagger$ & 29 & +61 & -167 & -196 & +23 & +10.8 \\
959 & 41 & +41 & -248 & -320 & -53 & +26.2 \\
967 & 23 & +31 & -106 & -150 & 0 & +16.8 \\
966 & 31 & -15 & -199 & -197 & -24 & -0.7 \\
970 & 32 & -59 & -241 & -196 & -133 & -16.7 \\
Average & 30 & +1 & -179 & -202 & -36 & +8.4
\end{tabular}

* Number of days each dog was on balance study before potassium administration; for details of protocol during this period see Methods.

$\dagger \mathrm{Kn}=\mathrm{K}$ corrected for $\mathrm{N}$.

$\ddagger$ Approximately $200 \mathrm{ml}$ of gastric drainage lost; balance data do not include a correction for this loss.

sium phosphate are shown in Figure 1. Detailed balance data for one of those studies ( $\operatorname{dog} 970$ ) are presented in Table II. Cumulative electrolyte and acid-base data for all studies are shown in Tables III and IV. Except for the partition of net acid excretion between ammonium and titratable acid, acid-base and electrolyte changes were virtually identical in the sulfate and phosphate groups.

Potassium. All dogs retained a significant quantity of potassium during the first 3 days of potassium ingestion, the mean cumulative retention being $124 \mathrm{mEq}$. Cumulative retention for the entire period averaged $133 \mathrm{mEq}$ (range, 91 to $241 \mathrm{mEq}$ ). Retention of this quantity of potassium did not appear to fully correct the loss that the animals had incurred during gastric drainage and the subsequent administration of a potassium-free diet (Table I); the remaining mean calculated deficit averaged $46 \mathrm{mEq}(\mathrm{Kn}, 69 \mathrm{mEq})$, but in view of the length of study it is difficult to be certain of the significance of this estimate. Mean plasma potassium concentration increased from 2.4 to 3.5

TABLE II

Balance data on a nonalkalotic, potassium deficient dog fed potassium sulfate (no. 970)

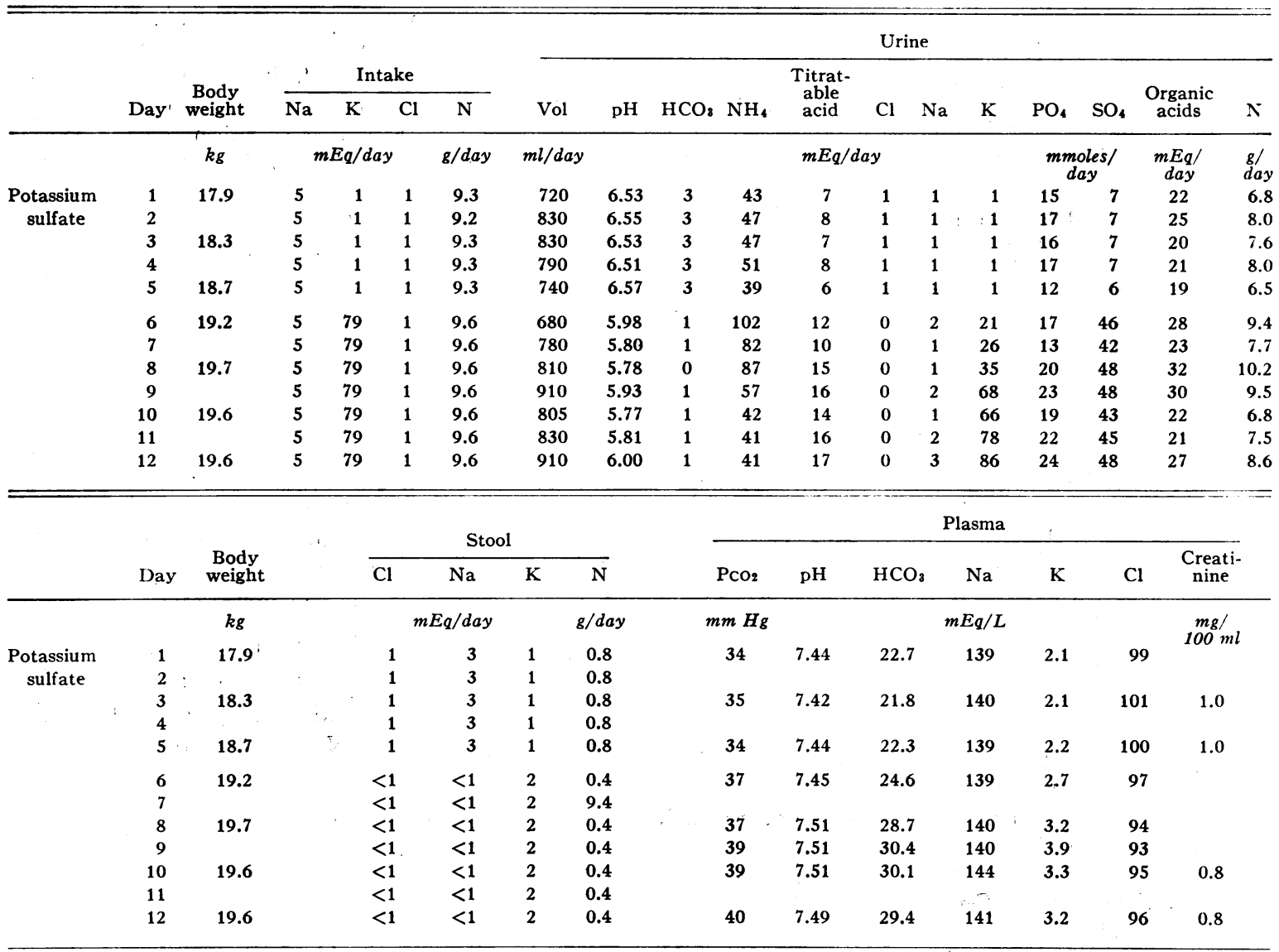


TABLE III

Cumulative balances during administration of potassium sulfate or neutral potassium phosphate to potassium-depleted dogs with normal extracellular acid-base parameters*

\begin{tabular}{|c|c|c|c|c|c|c|c|c|c|c|c|c|}
\hline \multirow[b]{3}{*}{ Dog } & \multirow{3}{*}{$\begin{array}{c}\text { Potassium } \\
\text { salt }\end{array}$} & \multirow[b]{3}{*}{ Days } & \multirow{2}{*}{\multicolumn{2}{|c|}{ Weight }} & \multirow{2}{*}{\multicolumn{5}{|c|}{ External balance }} & \multicolumn{3}{|c|}{ Internal balance } \\
\hline & & & & & & & & & & \multirow{2}{*}{$\begin{array}{l}\text { Intra- } \\
\text { cellular } \\
\mathrm{Na}\end{array}$} & \multirow{2}{*}{$\begin{array}{l}\text { Intra- } \\
\text { cellular } \\
\mathbf{K}\end{array}$} & \multirow{2}{*}{$\underset{\text { vol }}{\text { ECF } \dagger}$} \\
\hline & & & Initial & Final & $\mathrm{Na}$ & $\mathbf{K}$ & $\mathbf{K n}$ & $\mathrm{Cl}$ & $\mathbf{N}$ & & & \\
\hline & ' & & \multicolumn{2}{|c|}{ kg } & \multicolumn{4}{|c|}{$m E q$} & $g$ & \multicolumn{2}{|c|}{$m E q$} & $L$ \\
\hline 947 & Phosphate & 8 & 18.5 & 18.7 & +5 & +108 & +108 & -18 & +0.1 & -26 & +102 & +0.1 \\
\hline 958 & Phosphate & 7 & 19.1 & 19.1 & +7 & +91 & +81 & -6 & +3.8 & -8 & +.87 & +0.1 \\
\hline 959 & Phosphate & 7 & 26.3 & 26.6 & -57 & +241 & +239 & -4 & +0.8 & -109 & +237 & +0.2 \\
\hline 967 & Sulfate & 10 & 18.8 & 19.2 & -16 & +91 & +106 & -7 & -5.4 & -35 & +87 & +0.1 \\
\hline 966 & Sulfate & 7 & 21.9 & 22.4 & +5 & +108 & +104 & -7 & +1.4 & -30 & +104 & +0.2 \\
\hline 970 & Sulfate & 7 & 18.3 & 19.6 & +5 & +158 & +154 & -6 & +1.6 & -16 & +153 & +0.1 \\
\hline
\end{tabular}

* Neutral phosphate $=4 \mathrm{HPO}_{4} / 1 \mathrm{H}_{2} \mathrm{PO}_{4}$.

$+\mathrm{ECF}=$ extracellular fluid.

$\mathrm{mEq}$ per $\mathrm{L}$ during the period of potassium administration. This latter value was probably lower $(\mathrm{p}<0.02)$ than the mean value of $4.0 \mathrm{mEq}$ per $\mathrm{L}$ observed before gastric drainage when the animals were normal.

Acid-base (Figures 1 and 2). During the administration of potassium, plasma bicarbonate concentration increased from a mean control value of $22.1 \mathrm{mEq}$ per $\mathrm{L}$ to $28.4 \mathrm{mEq}$ per $\mathrm{L}$ (Figure 2); most of this rise occurred by the third day of potassium administration. Mean blood $\mathrm{pH}$ increased from 7.43 to 7.49 and mean plasma $\mathrm{Pco}_{2}$ from 35 to $39 \mathrm{~mm} \mathrm{Hg}$. Each of these changes was significant $(p<0.01)$.
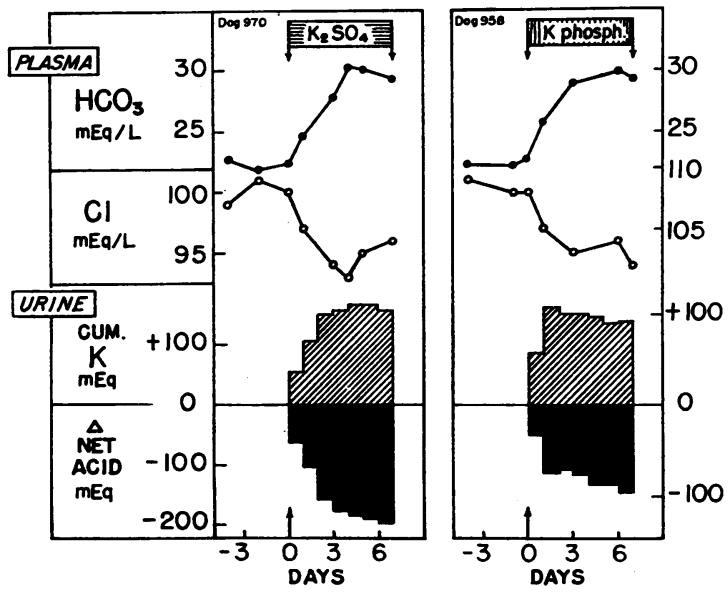

Fig. 1. EFFEcts of ADMINISTERING POTASSIUM SULFATE OR PHOSPHATE TO POTASSIUM-DEPLETED DOGS WITH NORMAL EXTRACELLULAR ACID-BASE PARAMETERS. Note than an increase in acid excretion is plotted downward from the base line, indicating a loss of acid from the body.
Net acid excretion increased strikingly during the first 3 days of potassium administration, the cumulative increment ranging from 67 and 156 $\mathrm{mEq}$ (average, $115 \mathrm{mEq}$ ). Daily excretion then promptly fell, but stabilized at a value averaging $9 \mathrm{mEq}$ per day above control levels; since over this latter interval there was no further rise in plasma bicarbonate concentration, it seems probable that the increased level of acid excretion in the new steady state reflected a slightly higher rate of endogenous acid production. Even if the values for net acid loss observed during the first 3 days of potassium administration are assumed to reflect such a change in acid production, and are corrected appropriately, the values for acid loss (mean, 88 $\mathrm{mEq}$ ) are still more than sufficient to account for the total bicarbonate added to the extracellular fluid.

TABLE IV

Comparison between potassium retention and acid loss during induction of alkalosis by administration of potassium sulfate or neutral potassium phosphate

\begin{tabular}{llcc}
\hline Dog & $\begin{array}{c}\text { Potassium } \\
\text { salt }\end{array}$ & $\begin{array}{c}\text { Cumulative } \\
\text { potassium } \\
\text { retention }\end{array}$ & $\begin{array}{c}\text { Cumulative } \\
\text { net } \\
\text { acid* }\end{array}$ \\
\hline 947 & Phosphate & +108 & -146 \\
958 & Phosphate & +91 & -96 \\
959 & Phosphate & +241 & -194 \\
967 & Sulfate & +91 & -116 \\
966 & Sulfate & +108 & -191 \\
970 & Sulfate & +158 & -196 \\
Mean & & +133 & -157 \\
& & &
\end{tabular}

* Cumulative loss of acid (i.e., increased excretion into the urine) is shown as a negative value and has been calculated as the change from the mean daily acid excretion during the 5 days preceding administration of potassium. 


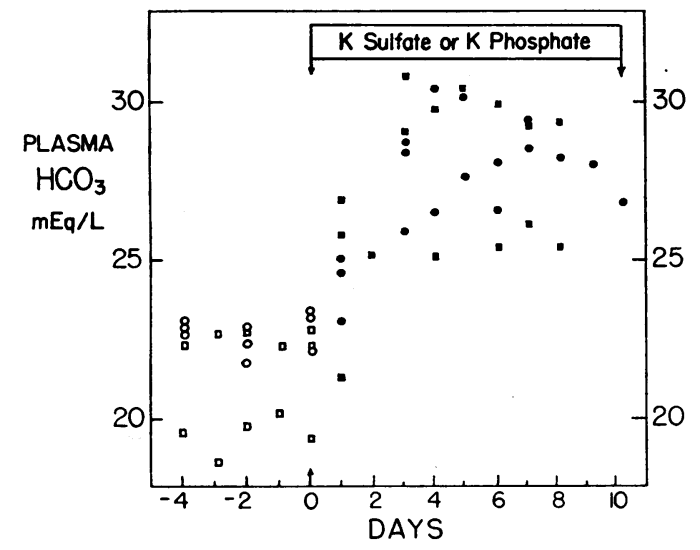

Fig. 2. Changes in plasma bicarbonate concentraTION DURING REPAIR OF POTASSIUM DEFICIENCY BY POTASSIUM SUlfate OR PHOSPHATE. Dogs that received potassium sulfate are represented by circles, dogs that received potassium phosphate by squares.

Sulfate, phosphate, and the partition of excreted acid between ammonium and titratable acid (Figure 3). Mean sulfate excretion increased from 8 to 46 mmoles per day when 39 mmoles of sulfate was added to the diet. Mean phosphate excretion increased from 19 to 58 mmoles per day when 44 mmoles of phosphate was added to the diet. There were no significant changes in phosphate excretion in the sulfate experiments, or in sulfate excretion in the phosphate experiments.

Although the increase in net acid excretion was comparable in the sulfate and phosphate groups, there was a striking difference in the partition of excreted acid between ammonium and titratable

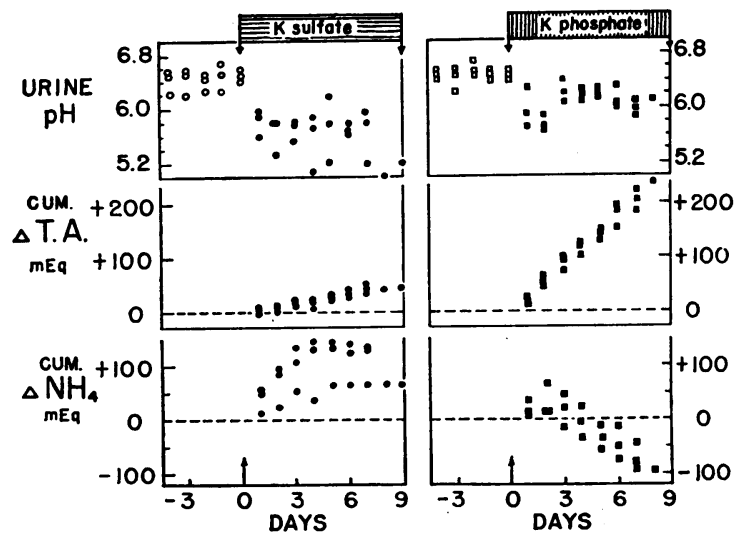

Fig. 3. Changes in URine pH, titratable acidity (TA), AND AMMONIUM EXCRETION DURING THE ADMINISTRATION OF POTASSIUM SULFATE OR PHOSPHATE TO POTASSIUM-DEPLETED DOGS WITH NORMAL EXTRACELLULAR ACIDBASE PARAMETERS. acid (Figure 3 ). In the sulfate studies a rise in ammonium excretion accounted for virtually the entire increment in net acid excretion; although urine $\mathrm{pH}$ decreased markedly, there was only a slight increase in titratable acid since phosphate excretion remained low.

In the phosphate studies, on the other hand, there was a large increase in the daily excretion of titratable acid that persisted throughout the period; daily ammonium excretion was either unchanged from control or slightly elevated during the first 2 to 3 days of phosphate administration, but thereafter decreased to a new level significantly lower than that of the period preceding phosphate administration. Urine $\mathrm{pH}$ decreased during the first 2 days of the period, but then returned approximately to control values.

Chloride, extracellular volume, and sodium. The urine remained essentially chloride free throughout the study. During the first 3 days of potassium administration, plasma chloride concentration fell by a mean of $5 \mathrm{mEq}$ per $\mathrm{L}$ (range, 3 to $6 \mathrm{mEq}$ ), and extracellular fluid volume expanded by a mean of $0.2 \mathrm{~L}$ (range, 0.1 to $0.3 \mathrm{~L}$ ), but each was essentially unchanged during the remainder of the period. There was a calculated shift of sodium out of cells that averaged 37 $\mathrm{mEq}$ and of potassium into cells that averaged 128 $\mathrm{mEq}$ (Table III). The mean final extracellular volume was not significantly different from the mean volume calculated for the same dogs before the original period of gastric aspiration.

There were no significant changes in plasma sodium concentration in any of the dogs or in external sodium balance in five of the six dogs. The one dog that lost sodium ( $\operatorname{dog} 959$ ) differed from the other animals in that it was the most potassium depleted, retained the largest amount of potassium, and had the largest calculated shift of sodium out of cells. In this animal, however, a significant fraction of sodium that had shifted from cells was retained in the extracellular fluid, and chloride space expanded by the same amount as in the other studies; this expansion took place before the first appearance of sodium in the urine.

Withdrawal of potassium sulfate and replacement by neutral potassium phosphate (two dogs)

Neither plasma bicarbonate concentration, blood $\mathrm{pH}$, nor urinary net acid excretion changed sig- 
nificantly when potassium phosphate was substituted for potassium sulfate. There was, however, a striking change in the partition of excreted acid between ammonium and titratable acidity. Substitution of neutral phosphate increased titratable acidity by an average of $23 \mathrm{mEq}$ per day, but this was accompanied by a decrease in ammonium excretion that averaged $21 \mathrm{mEq}$ per day. There were no significant changes in plasma sodium, potassium, or chloride concentration, or in the external balances of these ions.

\section{Withdrawal of neutral potassium phosphate from the diet (three dogs)}

When potassium phosphate was withdrawn from the diet, mean plasma potassium concentration decreased from $3.1 \mathrm{mEq}$ per $\mathrm{L}$ to $2.6 \mathrm{mEq}$ per $\mathrm{L}$, and there was a mean negative potassium balance of $90 \mathrm{mEq}$. Mean plasma bicarbonate concentration decreased by $1.6 \mathrm{mEq}$ per $\mathrm{L}$ (range, 0.9 to 2.1 ) and stabilized at a final average level of $28.4 \mathrm{mEq}$ per L. Cumulative net acid excretion (with the last 4 days of the potassium period as a reference) decreased by an average of $43 \mathrm{mEq}$ (range, 2 to $86 \mathrm{mEq}$ ). There were no significant changes in plasma concentrations of sodium or chloride or in the external balances of these ions.

\section{Miscellaneous}

Throughout the study body weight and plasma creatinine concentration remained essentially unchanged. Plasma unmeasured anion concentration increased from 20 to $22 \mathrm{mEq}$ per $\mathrm{L}$ during the period of potassium administration. Nitrogen balance averaged $+0.4 \mathrm{~g}$ during the period of potassium administration, $+4.2 \mathrm{~g}$ during the substitution of potassium phosphate for potassium sulfate, and $+5.5 \mathrm{~g}$ during withdrawal of potassium phosphate. Daily urinary organic acid excretion, analyzed in four dogs, showed no significant change during the period of potassium administration.

\section{Discussion}

The present studies were undertaken in an attempt to throw further light on the relationship between potassium deficiency and the regulation of renal acid excretion and bicarbonate reabsorption. For this purpose an experimental setting was chosen in which plasma bicarbonate concentration and $\mathrm{pH}$ were normal despite the presence of severe potassium deficiency, conditions conveniently provided by the dogs described in the previous paper (3) in which metabolic alkalosis was corrected by administration of hydrochloric acid and an electrolyte-free diet. The administration of potassium with a poorly reabsorbable anion has made it possible to determine whether, under these circumstances, the organism gives priority to conservation of sodium, to repair of potassium deficiency, or to maintenance of acid-base equilibrium. More specifically, the kidney is confronted with the following options: 1) The potassium deficiency can be ignored and the administered potassium excreted with the poorly reabsorbable anion. 2) Potassium can be retained, but only at the cost of losing either sodium or hydrogen in its place.

The data demonstrate that dogs confronted with these options retain potassium and, rather than excrete sodium, excrete a nearly equivalent quantity of hydrogen and develop metabolic alkalosis. ${ }^{1}$ The magnitude of this response is not influenced by the buffer characteristics of the administered anion, since sulfate, a nonbuffer, was just as effective as phosphate in producing the acid-base abnormalities. It is also of interest that the continued presence in the diet of potassium and the nonreabsorbable anion was not necessary for maintenance of alkalosis; withdrawal of the potassium salt led to only a slight fall in plasma bicarbonate concentration.

These data, viewed in light of current concepts of renal tubular function, would appear to be best accounted for in the following fashion: When the administered potassium and poorly reabsorbable anion are initially presented to the kidney, potassium is reabsorbed in the proximal tubule with chloride, thus shunting sodium with poorly reabsorbable anion to a distal exchange site. Here the sodium is exchanged in part with potassium but also to a considerable extent with hydrogen, the sum of the two approximating the quantity of potassium that had been administered. ${ }^{2}$ To the ex-

\footnotetext{
1 Administration of a similar quantity of potassium phosphate to normal dogs on the same chloride-free diet does not induce metabolic alkalosis (1).

2 It seems probable that some portion of the administered potassium entered body cells in exchange for sodium and hydrogen before it had the opportunity to appear in the glomerular filtrate. The net effect of this event would also be to increase the presentation of sodium
} 
tent that additional hydrogen is excreted into the urine, potassium is retained in the body with bicarbonate. A portion of this potassium enters cells in exchange with hydrogen, the net result being an alkalinization of both the intra- and extracellular compartments. Most of the remaining potassium exchanges with sodium and allows extracellular fluid to expand approximately to its normal volume. As a result of this expansion (which is sustained by renal conservation of sodium), serum chloride concentration falls, the fraction of filtered sodium that is reabsorbed by cation exchange is increased, and the rate of hydrogen ion secretion and bicarbonate reabsorption is elevated $(1,2)$. Parenthetically, it should be pointed out that the present study tends to exclude the possibility, raised by previous experiments, that contraction of the extracellular space is responsible for the alkalosis induced by chloride depletion and hypochloremia $(1,2)$.

These experiments do not, of course, delineate the changes in potassium concentration or $\mathrm{pH}$ that may have occurred within renal tubular cells, but it seems reasonable to assume that the repletion of body potassium stores and the systemic alkalinization would be shared by the renal tubular cells. The possibility cannot be excluded, however, that the composition of renal tubular cells did not parallel that of the blood and body tissues generally, but rather that these cells became potassium deficient and acidotic. To account for the observed augmentation of acid excretion on this basis, we must also postulate that before the administration of potassium the potassium-depleted dogs had normal tubular potassium stores; as has been discussed previously, this seems unlikely (3).

If a direct relationship is assumed to exist between the potassium content of the body and of the renal tubules, the present experimental observations can still readily be accounted for within the theoretical framework (derived from acute experiments) that relates the secretion of potassium and hydrogen $(5,6)$. The following explanation is proposed: When potassium sulfate (or phosphate) is administered and an increased quantity

and poorly reabsorbable anion to distal exchange sites; under such circumstances, however, the increase in sodium-hydrogen exchange would take place without the intervention of potassium reabsorption in the proximal tubule. of sodium is delivered to the exchange site for reabsorption, a deficiency of potassium combined with a normal availability of hydrogen favors the secretion of hydrogen rather than potassium. Although the renal tubular potassium stores are undergoing partial repair, the continued presence of a significant degree of cellular potassium depletion allows a large fraction of the cation secretion to consist of hydrogen. As tubular potassium stores become progressively repleted, more potassium becomes available for secretion, potassium contributes a progressively larger share of the exchange package, and further loss of hydrogen ceases.

By contrast with the present study, the alkalosis induced by the gastric drainage of hydrochloric acid is associated with a loss of potassium, a finding also readily explained within the conventional theoretical framework. During the depletion of hydrochloric acid, sodium previously reabsorbed with chloride is shifted to the cation exchange mechanism with the result that potassium and hydrogen secretion is accelerated (2). Since cellular potassium stores are intact, potassium comprises a relatively large fraction of the exchange; bicarbonate is, therefore, permitted to escape into the urine, and the development of alkalosis is retarded. As potassium stores become depleted, and the demand for a high rate of cation exchange continues, hydrogen secretion claims a progressively larger share of the common secretory pathway until a new steady state of potassium balance, hypochloremia, and alkalosis is achieved. Both in the alkalosis induced by gastric drainage and in that induced by potassium sulfate the final steady state is similar, but the approach to this state involves depletion of renal potassium stores in one case and partial repletion in the other.

Finally, it is noteworthy that the rise in net acid excretion was virtually identical whether potassium was administered with sulfate or with phosphate; with potassium phosphate, however, this increase occurred almost entirely as titratable acid, whereas with sulfate it occurred as ammonium. In addition, when phosphate was substituted for sulfate, daily net acid excretion did not change. These observations indicate that total acid excretion was not a function of the buffer characteristics of the poorly reabsorbable anion. 


\section{Summary}

Potassium deficient dogs, in which the acid-base composition of extracellular fluid was normal, were maintained on an electrolyte-free diet and subsequently fed a potassium supplement as either sulfate or neutral phosphate. This protocol was designed to confront the kidney with the following options. It could 1) ignore the potassium deficit and excrete potassium with the poorly reabsorbable anion or 2) retain potassium and excrete either sodium or hydrogen in its place. The data indicate that in each instance there was a marked retention of potassium and an approximately equivalent loss of acid into the urine. Concomitantly, plasma bicarbonate concentration and $\mathrm{pH}$ increased to frankly alkalotic levels, and plasma potassium concentration rose towards normal. Once alkalosis had developed, it persisted even after potassium and the poorly reabsorbable anion were withdrawn from the diet. It is thus clear that repair of potassium deficiency and protection of volume took priority over maintenance of normal acid-base equilibrium. Current views on the interrelationship between potassium deficiency and metabolic alkalosis have been examined in light of these findings.

\section{References}

1. Gulyassy, P. F., C. Van Ypersele De Strihou, and W. B. Schwartz. On the mechanism of nitrateinduced alkalosis. The possible role of selective chloride depletion in acid-base regulation. J. clin Invest. 1962, 41, 1850.

2. Needle, M. A., G. J. Kaloyanides, and W. B. Schwartz. The effects of selective depletion of hydrochloric acid on acid-base and electrolyte equilibrium. J. clin. Invest. 1964, 43, 1836.

3. Tannen, R. L., H. L. Bleich, and W. B. Schwartz. The renal response to acid loads in metabolic alkalosis; an assessment of the mechanisms regulating acid excretion. J. clin. Invest. 1966, 45, 562.

4. Kassirer, J. P., and W. B. Schwartz. Correction of metabolic alkalosis in man without repair of potassium deficiency. A reevaluation of the role of potassium. Amer. J. Med. 1966, 40, 19.

5. Berliner, R. W. Renal secretion of potassium and hydrogen ions. Fed. Proc. 1952, 11, 695.

6. Berliner, R. W., T. J. Kennedy, Jr., and J. Orloff. Relationship between acidification of the urine and potassium metabolism. Effect of carbonic anhydrase inhibition on potassium excretion. Amer. J. Med. 1951, 11, 274. 